\title{
Normas europeas de cementos
}

\author{
M. I. SÁNCHEZ DE ROJAS, M. FRÍAS y N. GARCÍA \\ ICCET/CSIC \\ ESPAÑA
}

Fecha de recepción: 26-VII-93

\section{RESUMEN}

Este artículo se basa en la conferencia pronunciada en los "Seminarios Torroja", dedicados a la "Tecnología de la Construcción y sus Materiales", por M. a Isabel Sánchez de Rojas, Colaboradora Científica del Instituto Eduardo Torroja, cuya disertación versó sobre "Normas europeas de cementos".

\author{
$S \cup M M A R Y$ \\ This article is based on the lecture, by Dr. M. ${ }^{a}$ Isabel \\ Sánchez de Rojas (Senior Researcher at the Eduardo \\ Torroja Institute) and it is entitled "European Cement \\ Standars" which was given in the framework of \\ SEMINARIOS TORROJA, Building Technology and \\ Materials.
}

\section{INTRODUCCIÓN}

Este trabajo pretende destacar las novedades que presenta la normativa europea con respecto a las normas UNE actuales.

Estas diferencias no son muy significativas gracias a que la normativa española se ha ido adaptando, en los últimos años, a las nuevas tendencias europeas en materia de Normalización de cementos.

Así, la Comisión 80 del IRANOR, hoy Comité 80 de AENOR, ha elaborado normas en consonancia con las normas $\mathrm{CEN}$, que recogen definiciones, denominaciones, composición y especificaciones, tanto de los cementos como de sus componentes, así como sobre el control de calidad de los mismos. Todo ello con el fin de garantizar la seguridad y durabilidad del producto resultante.

A continuación se expone y comenta todo aquello relacionado con los cementos y su normativa, así como sobre su control de calidad.

\section{LA NORMALIZACIÓN Y LA CERTIFICACIÓN}

En febrero de 1986 se designa a la Empresa "Asociación Española de Normalización" (AENOR) como Entidad reconocida para desarrollar tareas de Normalización y Certificación, y asume las funciones que venía realizando el Instituto Español de Normalización (IRANOR).

La Normalización se establece en base a un compromiso social a partir del cual fabricantes, usuarios y Administración se ponen de acuerdo para determinar las normas específicas que definen un producto o servicio.

En el seno de AENOR existen Comités Técnicos de Normalización, responsables de la elaboración de proyectos de normas, en base a un consenso obtenido entre todos los que intervienen en su ejecución.

También en AENOR se establecen Comités de Certificación, cuyo objeto es verificar que los productos son conformes con las normas que les son aplicables, sirviendo al mismo tiempo para implantar en las empresas sistemas que aseguren la calidad a través de la concesión de marcas.

\section{NORMAS UNE PARA CEMENTOS}

En las Normas UNE 80301 y 80302 , se recogen las definiciones, clasificación y especificaciones para el cemento y sus componentes: 
* Norma 80 301: "Cementos: definiciones, clasificación y especificaciones".

* Norma 80 302: "Cementos: especificaciones químicas para sus componentes".

De igual forma, los cementos que presentan alguna característica especial están definidos en las Normas UNE 80303 y UNE 80 305:

- Norma UNE 80 303: "Cementos: cementos con características especiales"

- Norma UNE 80 305: "Cementos portland blan$\cos ^{\prime \prime}$

En estas normas los cementos se designan por su tipo y clase y, en su caso, por sus características especiales.

En la norma UNE 80301 se recogen seis variedades diferentes de cementos, en los que es posible encontrar cementos binarios, terciarios e incluso cuaternarios, así como un cemento exento de adición. La principal justificación a este hecho es la armonización con la Norma CEN, que se expone a continuación.

\section{NORMAS EUROPEAS}

El Comité Técnico CEN/TC 51 ha sido el encargado de la redacción de una Norma Europea sobre cementos, que recogiese: Composición, Especificaciones y Criterios de Conformidad para los mismos.

En abril de 1992, la ENV 197-1 fue aprobada como Norma Europea Experimental, aunque se inició su elaboración a principios de los años 80 . Esta Norma Experimental se somete a los miembros del CEN para su voto formal y tiene una validez inicial de tres años, que pueden prorrogarse 2 años más, en los que el documento se estudia y puede modificarse, hasta pasar a Norma EN definitiva.

Las normas nacionales existentes que discrepen con la norma europea, pueden mantenerse en aplicación (paralelamente a la ENV) hasta la decisión final de posible conversión de ENV en EN.

A la vista del amplio número de cementos a tener en cuenta, el CEN/TC 51 ha decidido dividir la ENV 197 en varias partes. Así, en la ENV 197-1, solamente se han tomado en consideración aquellos cementos cuyo endurecimiento depende principalmente de la hidratación de los silicatos cálcicos del clínker portland, y que se suministran para empleo general. Los cementos con distintos endurecimientos o propiedades especiales adicionales serán contemplados en las partes siguientes de la prenorma europea: ENV 197-2, ENV 197-3, etc.
De este modo, se tiene previsto una norma europea, que sería designada como CEN/EN 197-10, sobre cemento aluminoso. Esta norma dispondrá de dos partes: una dedicada a la descripción del producto y otra a las normas de correcto empleo del mismo con fines estructurales. En el comité de redacción participan, por el momento, miembros de países fabricantes de dicho cemento (Francia, Reino Unido y España), así como miembros de otros paises interesados (Alemania e Italia).

En la prenorma ENV 197-1 se recogen los tipos de cementos, su composición y designación, así como los requisitos mecánicos, físicos y químicos de los mismos, tal y como lo hace la Norma UNE 80301 88 , y también las especificaciones químicas para los constituyentes de los cementos, igual que aparecen en la Norma UNE 8030290.

Por otro lado, los criterios de conformidad aparecen igualmente en esta norma ENV 197-1, y abarca la Norma UNE 80403 sobre: "Cementos control de producción. Criterios de conformidad".

Lo referente a métodos de ensayo se encuentran recogidos en la EN 196 en los diferentes apartados. Así, en la EN 196-1 se presentan "la determinación de la resistencia mecánica", en la EN 196-2 "Análisis químico del cemento", en la EN 196-3 "determinación del tiempo de fraguado y estabilidad", etc.

\section{DIFERENCIAS $Y$ SEMEJANZAS ENTRE LAS NORMAS UNE 8030188 , UNE 80302 Y LA ENV 197-1}

En la Tabla de Tipos de Cementos, Composición y Designación correspondiente a la Norma ENV 197-1, se observa que existen diferencias con respecto a la Clasificación de Cementos de la Norma UNE 80301 88, que se comentarán posteriormente con detenimiento.

Sin embargo, las mayores variaciones aparecen en lo referente a los componentes del cemento.

\section{COMPONENTES DEL CEMENTO}

Las especificaciones de carácter químico, correspondientes a los distintos componentes de los cementos recogidos en la Norma UNE 8030188 , se presentan en la Norma 8030290 .

Estas especificaciones tienen por objeto asegurar un buen comportamiento de los materiales, evitando posibles efectos no deseados en morteros u hormigones.

Entre estos constituyentes, algunos de ellos se 
TABLA I

Constituyentes principales

\begin{tabular}{|c|c|c|c|}
\hline \multicolumn{2}{|c|}{ ENV 197-1 } & \multicolumn{2}{|c|}{ UNE $80302 / 80301$} \\
\hline Constituyente & Designación & Constituyente & Designación \\
\hline \multirow[t]{2}{*}{ Clinker portland } & K & Clínker portland & - \\
\hline & & Clínker aluminoso & - \\
\hline Escoria de horno alto & s & Escoria de horno alto & $\mathrm{S}$ \\
\hline Puzolana natural & $P$ & Puzolana natural & z \\
\hline Puzolana industrial & Q & \multirow{3}{*}{ Otras puzolanas artificiales } & \multirow{3}{*}{ - } \\
\hline Esquisto calcinado & $\mathrm{T}$ & & \\
\hline Humo de sílice & D & & \\
\hline Ceniza volante silícea & v & \multirow{2}{*}{ Ceniza volante } & \multirow{2}{*}{ C } \\
\hline Ceniza volante cálcica & W & & \\
\hline Caliza & L & Filler calizo & $\mathrm{F}$ \\
\hline Filler & $\mathrm{F}$ & & \\
\hline Sulfato de calcio & - & & \\
\hline Aditivos & - & Aditivos & - \\
\hline
\end{tabular}

TABLA II

Especificaciones químicas para los componentes de los cementos (Norma UNE 80302 )

\begin{tabular}{|c|c|c|}
\hline COMPONENTE & ESPECIFICACIÓN & VALOR \\
\hline Clínkeres portland & $\begin{array}{l}\text { - Silicato cálcico } \\
\text { * Relación } \mathrm{CaO} \% / \mathrm{SiO}_{2} \% \\
\text { * MgO }\end{array}$ & $\begin{array}{l}2 / 3 \\
\geq 2 \\
\leq 5 \%\end{array}$ \\
\hline Clínkeres aluminosos & * Óxido de aluminio & $\geq 36 \%$ \\
\hline Escorias de horno alto & $\begin{array}{l}\text { * Fase vítrea } \\
* \mathrm{CaO}+\mathrm{MgO}+\mathrm{SiO}_{2} \\
\therefore[\mathrm{CaO} \%+\mathrm{MgO} \%] / \mathrm{SiO}_{2}\end{array}$ & $\begin{array}{l}\geq 2 / 3 \\
\geq 2 / 3 \\
>1\end{array}$ \\
\hline Puzolanas naturales & $\begin{array}{l}\text { *al reactiva } \\
\text { * Sílice reactiva }\end{array}$ & $\begin{array}{l}\text { Insignificante } \\
\geq 25 \%\end{array}$ \\
\hline Cenizas volantes & $\begin{array}{l}\text { * Cal } \\
\text { * Sílice reactiva }\end{array}$ & $\begin{array}{l}<5 \% \\
\geq 25 \%\end{array}$ \\
\hline Otras puzolanas artificiales & $\begin{array}{l}\text { * Ausencia de sustancias nocivas } \\
\text { * Sílice reactiva } \\
\text { * Ensayo de puzolanicidad para los cementos que las contengan }\end{array}$ & $\geq 25 \%$ \\
\hline Filler calizo & * $\mathrm{CaCO}_{3}$ & $>85 \%$ \\
\hline Aditivos & * Ausencia de efectos perjudiciales & \\
\hline
\end{tabular}


recogen en la Norma UNE 80302 , pero otros no están especificados en ésta o lo están de forma más detallada en la ENV 197-1.

En la tabla I se señalan los diferentes componentes o constituyentes existentes en ambas normas.

En las especificaciones recogidas en la Norma UNE 80 302, tabla II, se establece que:

* Clínkeres portland deben estar compuestos, al menos en dos tercios de su masa, por silicatos de calcio. El resto debe estar formado por compuestos de óxido de aluminio, óxido de hierro y otros óxidos.

La relación $\mathrm{CaO} / \mathrm{SiO}_{2}$ no debe ser inferior a 2 y el contenido de óxido de magnesio no debe ser superior al $5 \%$.

* Clínkeres aluminosos deben contener óxido de aluminio en proporción no inferior al $36 \%$.

* Escorias de horno alto deben estar constituidas, al menos en dos tercios de su masa, por fase vitrea.

Así mismo, deben estar compuestas al menos en dos tercios de su masa por $\mathrm{CaO}, \mathrm{MgO}$ y $\mathrm{SiO}_{2}$. El resto debe estar formado por óxidos de aluminio y pequeñas cantidades de otros óxidos.

La relación $(\mathrm{CaO}+\mathrm{MgO}) / \mathrm{SiO}_{2}$ debe ser superior a 1.

* Las Puzolanas naturales y cenizas volantes tienen que estar constituidas esencialmente por sílice reactiva y alúmina, así como por pequeñas cantidades de óxidos de hierro y otros óxidos.

En el caso de las puzolanas naturales y cenizas volantes, se presentan los conceptos de sílice y cal reactiva.

Se considera sílice reactiva la cantidad de sílice que, después de la disolución en ácido clorhídrico, se disuelve por ataque con hidróxido de potasio a ebullición. Para evaluar dicha sílice reactiva del dióxido de silicio total se resta el que queda en el residuo insoluble en ácido clorhídrico e hidróxido de potasio.

La cal reactiva es la fracción de óxido de cal total que, en condiciones de endurecimiento normal, puede formar compuestos de calcio hidratados. Para evaluar dicha fracción, se deducirá del total de óxido de calcio la parte supuestamente combinada como carbonato $\left(\mathrm{CaCO}_{3}\right)$ y calculada sobre la base de la determinación del contenido de dióxido de carbono $\left(\mathrm{CO}_{2}\right)$, así como la parte supuestamente combinada como sulfato $\left(\mathrm{CaSO}_{4}\right)$ y calculada sobre la base de la determinación del contenido de trióxido de azufre $\left(\mathrm{SO}_{3}\right)$.

En el caso de las cenizas volantes se especifica que cuando éstas tengan un contenido de $\mathrm{CaO}$ superior al $5 \%$ pueden tener hidraulicidad latente, así como propiedades puzolánicas, pero pueden dar lugar a inestabilidad de volumen y, por tanto, los cementos que contengan cenizas de este tipo deberán de ser sometidos a un severo control de estabilidad de volumen.

* En la norma UNE 80302 se recogen también otras puzolanas artificiales, como las arcillas térmicamente activadas, el humo de sílice, las escorias de las metalurgias de cobre, cinc y plomo, y de las ferroaleaciones que cumplan con las siguientes especificaciones:

- su contenido de sílice reactiva no debe ser inferior al $25 \%$;

- su proporción no será superior a la máxima especificada para los cementos puzolánicos (40\%) y cumplir el ensayo de puzolanicidad;

- no contener sustancias nocivas.

* Los filleres calizos deben contener carbonato de calcio en proporción superior al $85 \%$.

* Los aditivos no tienen especificaciones concretas, pero se indica que no deberán provocar efectos perjudiciales.

En la ENV 197-1, tabla III, el clínker y las escorias de horno alto tienen las mismas especificaciones que las recogidas en la Norma UNE 80302 . Sin embargo, existen diferencias en lo referente a los demás constituyentes.

Así, a las puzolanas se les exige los mismos requisitos en las ENV 197-1 y en la norma UNE mencionada, en relación a la sílice y cal reactiva. Sin embargo, en la ENV se menciona que los materiales puzolánicos deben de prepararse correctamente, es decir, deben ser seleccionados, homogeneizados, secados y pulverizados, dependiendo de su estado en la producción o en el suministro, con ello se quiere asegurar que éstos se adicionan en unas condiciones apropiadas para que pueda darse la reacción puzolánica.

También, en la norma europea se distingue, como ya se ha indicado, entre puzolanas naturales y puzolanas industriales.

Las primeras son aquellos materiales de origen volcánico o sedimentario, con composición química y mineralógica adecuadas. 
TABLA III

Constituyentes ENV 197-1

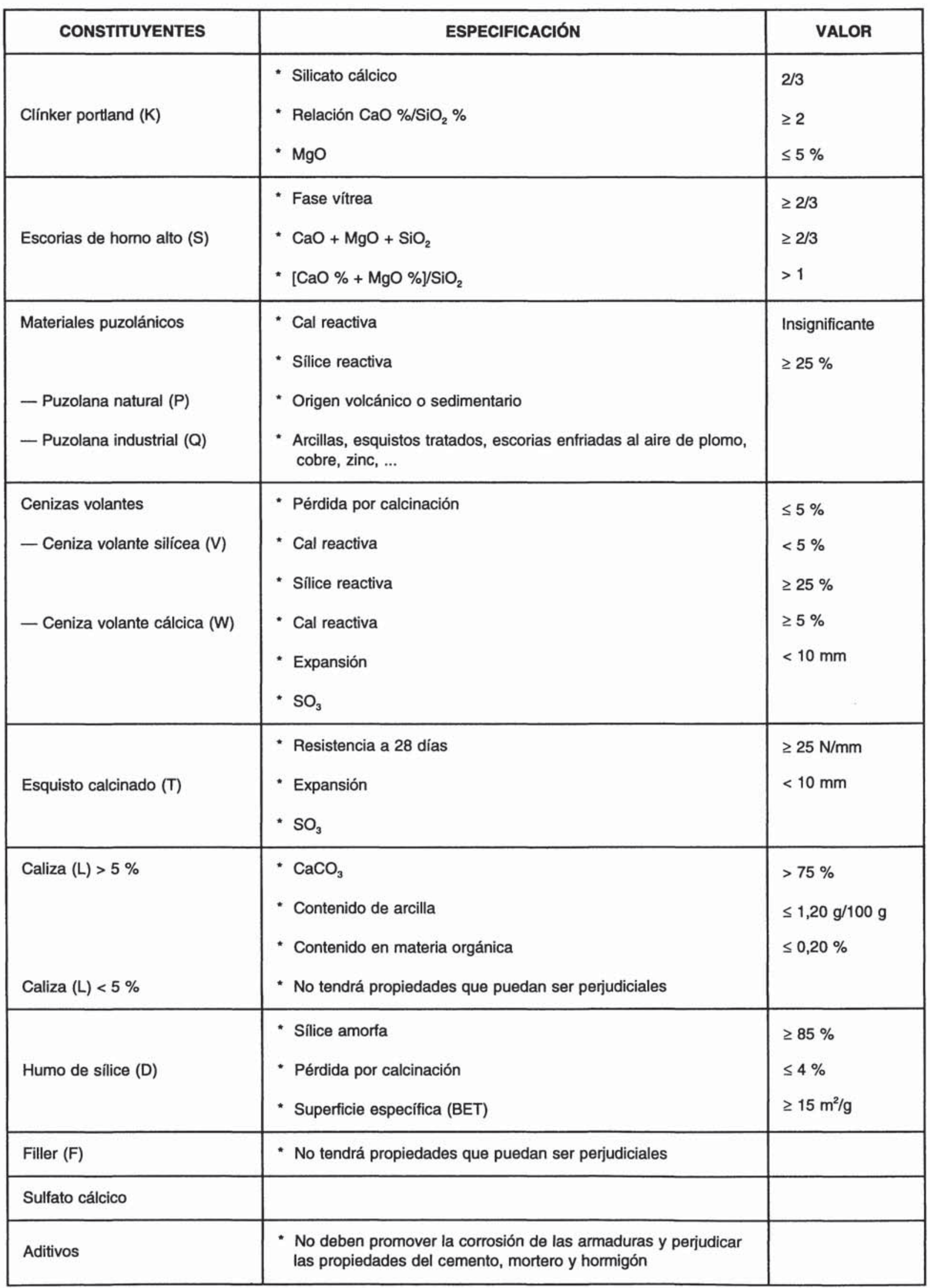


Las puzolanas industriales son arcillas y esquistos tratados y activados térmicamente, escorias enfriadas al aire de plomo, cobre, zinc y otros productos procedentes de la industria de las ferroaleaciones, que cumplan con las especificaciones indicadas para los materiales puzolánicos.

Además, se exige que no aumenten la demanda de agua del cemento, que no disminuyan la resistencia del hormigón o del mortero ante cualquier tipo de deterioro, ni que reduzcan la protección de las armaduras frente a la corrosión.

En el caso de las cenizas volantes, se distinguen en la ENV dos tipos diferenciados: las cenizas volantes silíceas y las cenizas volantes cálcicas, estas últimas son aquellas que pueden presentar, además de propiedades puzolánicas, propiedades hidráulicas debidas a su contenido en cal.

En ambos casos se especifica que la pérdida por calcinación no excederá del $5 \%$ en masa. Esta especificación, que no se contempla en la norma UNE, se debe a la influencia de los inquemados, cuya presencia se pone de relieve por esta determinación.

Los restos de carbón en el cemento pueden dar lugar a alteraciones en el fraguado y endurecimiento del mismo, y perjudicar el efecto de los aditivos empleados.

En las cenizas volantes de naturaleza silicea se contemplan las especificaciones de la sílice reactiva y cal reactiva.

La ceniza volante cálcica que contenga entre $5 \%$ y $15 \%$ de cal reactiva $\mathrm{CaO}$, no debe contener menos de $25 \%$ en masa de sílice reactiva.

La ceniza volante cálcica, finamente molida, que contenga más de $15 \%$ de cal reactiva, debe presentar una resistencia a la compresión de 10 $\mathrm{N} / \mathrm{mm}^{2}$ a 28 días cuando se ensaya según EN 196-1 modificada (moler la ceniza hasta que la masa de la ceniza retenida por el tamiz de $40 \mu \mathrm{m}$ en húmedo esté comprendida entre $10 \%$ y $30 \%$ en masa. El mortero se prepara solamente con el material a ensayar, en lugar de cemento y en unas condiciones de curado determinadas).

En estas cenizas de naturaleza cálcica se contempla además la expansión, que deberá ser menor de $10 \mathrm{~mm}$ (ensayo descrito en EN 196-3, mezcla $30 \%$ de material a ensayar y $70 \%$ cemento de referencia: CEM I)

También en estos materiales, si el $\mathrm{SO}_{3}$ excede del autorizado para los cementos de los que forma parte $(3,5 \%-4,0 \%)$, se deberá tener en cuenta a la hora de dosificar adecuadamente los materiales que contengan $\mathrm{CaSO}_{4}$.

Los esquistos calcinados aparecen diferenciados en la norma ENV. Se define como un material producido en un horno a $800^{\circ} \mathrm{C}$, que por su composición tiene fases mineralógicas del clínker portland, y un cierto contenido de $\mathrm{CaO}$ libre, sulfato cálcico y óxidos con actividad puzolánica, especialmente sílice.

\section{Para este material se especifica:}

- Con el material finamente molido, se prepara un mortero (solamente con el material a ensayar, en lugar de cemento) y en unas condiciones de curado determinadas, dando una resistencia mínima de $25 \mathrm{~N} / \mathrm{mm}^{2}$ a los 28 días.

La expansión será menor de 10 mm (Ensayo descrito en EN 196-3, mezcla $30 \%$ de material a ensayar y $70 \%$ cemento de referencia: CEM I)

$\mathrm{Si}$ el $\mathrm{SO}_{3}$ excede del autorizado para los cementos de los que forma parte $(3,5 \%-4,0 \%)$, se deberá tener en cuenta a la hora de dosificar adecuadamente los materiales que contengan $\mathrm{CaSO}_{4}$.

En la caliza se distingue si ésta se emplea como constituyente principal ( $>5 \%$ ) o en proporción inferior al $5 \%$.

En el caso de tratarse de un constituyente principal, el contenido de $\mathrm{CaCO}_{3}$ será superior al $75 \%$ en masa, en vez del $85 \%$ establecido en la norma UNE.

Otra diferencia con la norma española está en la especificación del contenido de arcilla $(1,2 \mathrm{~g} / 100 \mathrm{~g}$, según el método de azul de metileno) y en materia orgánica (TOC) $(0,20 \%)$, las calizas con contenido de materia orgánica comprendida entre 0,2 y 0,5 podrán utilizarse si el cemento tiene un comportamiento aceptable.

El humo de sílice es otro de los materiales que dan lugar a cementos diferenciados en la ENV y no en la norma UNE.

A este material, si se emplea como constituyente principal (>5\%), se le exige un contenido mínimo de silice amorfa, un valor máximo de pérdida por calcinación y una finura expresada como superficie especifica BET.

Como filler se recogen materiales inorgánicos minerales, naturales o artificiales, inertes o con propiedades puzolánicas que, mediante adecuada preparación, teniendo en cuenta su distribución granulométrica, mejoran las propiedades físicas de 
los cementos (trabajabilidad o retención de agua).

Estos materiales tendrán que ser preparados correctamente y no presentar efectos perjudiciales.

Con respecto al sulfato cálcico - recogido en la norma UNE como regulador de fraguado-y a los aditivos en la ENV no se incluye ninguna especificación sobre los mismos.

\section{TIPOS DE CEMENTOS}

Los tipos de cementos recogidos en la norma UNE 80301 y en ENV 197-1, se presentan de forma comparativa en la tabla IV.

* Tanto en la Norma UNE 80301 como en la ENV se excluye el regulador de fraguado o sulfato cálcico y los aditivos en la composición de los cementos. Por lo tanto, el cemento final debe comprender el núcleo más sulfato de calcio necesario y los aditivos si los hubiere.

* En la ENV aparecen 5 Tipos principales de cementos, mientras que en la Norma UNE aparecen 6 Tipos. Esto es así debido a que el cemento aluminoso no es recogido en la ENV 197-1 y, como ya se ha mencionado, será objeto de atención en otra parte de esta norma.

* El cemento Tipo I-O, recogido en la Norma UNE, no se encuentra en la ENV.

* El cemento Tipo I de la Norma UNE puede tener un contenido de clínker entre el $95 \%$ y $99 \%$, existiendo la posibilidad de que lleve incorporado del $1 \%$ al $5 \%$ de componentes adicionales, sin embargo el Tipo I de la ENV puede llevar incorporado de $0 \%$ a $5 \%$ de constituyentes minoritarios adicionales.

* En los demás tipos de cementos el contenido de componentes adicionales, según la Norma UNE, y constituyentes minoritarios adicionales, según la norma ENV, van del $0 \%$ al $5 \%$, por lo que ambas normas coinciden en este criterio.

* En la mayoría de los cementos de la ENV, aparecen 2 ó 3 Tipos diferentes, designados como A, B y $C$, que se diferencian en el contenido de clínker $y$, por tanto, en el contenido de materiales adicionados.

* En los cementos Tipo // se distinguen, de forma explícita e independiente, un mayor número de adiciones.

- El cemento portland con humo de sílice, que no aparece como tal en la Norma UNE, permite incorporar hasta un $10 \%$ de humo de sílice.

- Las escorias no férreas pueden ser incorporadas hasta un $15 \%$.

* En los cementos portland compuestos se limita el contenido de filler al $5 \%$. Además de clínker deben tener incorporado al menos dos constituyentes considerados principales, aunque no tienen que cumplir ninguna exigencia en proporción como ocurre en la norma UNE 80301 , en la que se recoge una fórmula para el porcentaje de los componentes.

* La Norma ENV establece tres Tipos de cementos de horno alto, de forma que el Tipo III/C presenta porcentajes de escoria hasta el $95 \%$, mientras que la Norma UNE solamente establece contenidos, en el Tipo III-2, hasta el $80 \%$.

* En el cemento Tipo IV se excluye, en la ENV, como constituyente a las cenizas volantes cálcicas.

* El cemento Tipo $V$ de la Norma UNE es diferente del recogido como Tipo $\mathrm{V}$ en la ENV, ya que en ésta última la escoria de alto horno está siempre presente, aunque también pueden incorporarse puzolanas y cenizas volantes silícicas.

Tal vez el cemento Tipo $\mathrm{V}$, según la norma UNE, pueda ser contemplado en otro apartado de la ENV 197 , en un futuro, como cemento con propiedades especiales, aunque este tipo de cemento de la norma UNE está comprendido en el cemento puzolánico Tipo IV de la ENV.

\section{Exigencias mecánicas}

Las diferencias principales en las exigencias mecánicas entre ambas normativas, son:

En general, la ENV 197-1 presenta valores para las categorias resistentes menores que la norma UNE:

Valores de resistencias (en $\mathrm{N} / \mathrm{mm}^{2}$ )

\begin{tabular}{|c|c|}
\hline ENV 197-1 & UNE 80 301 \\
\hline- & 55 \\
52,5 & - \\
- & 45 \\
42,5 & - \\
- & 35 \\
32,5 & - \\
- & 25 \\
\hline
\end{tabular}


TABLA IV

Diferencias y semejanzas normas UNE 8030188 y ENV 197-1

\begin{tabular}{|c|c|c|c|c|}
\hline \multirow{2}{*}{ DESIGNACIÓN } & \multicolumn{2}{|r|}{ UNE 8030188} & \multicolumn{2}{|r|}{ ENV 197-1 } \\
\hline & Tipo & Composición & Tipo & Composición \\
\hline Portland & $\begin{array}{l}1-0 \\
1\end{array}$ & $\begin{array}{l}100 \% \text { Clínker } \\
\text { 95-99 \% Clínker } \\
\text { 1-5-\% Adición }\end{array}$ & 1 & $\begin{array}{l}\text { 95-100 \% Clínker } \\
\text { 0-5 \% Adición }\end{array}$ \\
\hline Portland compuesto & II & $\begin{array}{l}65-88 \% \text { Clínker } \\
\leq 35 \% \text { C. Prin. (+) }\end{array}$ & II/A-M & $\begin{array}{l}\text { 80-94 \% Clínker } \\
\text { 6-20 \% C. Prin. (*) } \\
\text { 65-79\% Clinker } \\
21-35 \% \text { C. Prin. (*) }\end{array}$ \\
\hline Portland con escoria & II-S & $\begin{array}{l}65-94 \% \text { Clínker } \\
6-35 \% \text { S } \\
0-5 \% \text { Adición }\end{array}$ & $\begin{array}{l}\text { II/A-S } \\
\text { II/B-S }\end{array}$ & $\begin{array}{l}\text { 80-94 \% Clínker } \\
6-20 \% \text { S } \\
0-5 \% \text { Adición } \\
65-79 \% \text { Clínker } \\
21-35 \% \text { S } \\
0-5 \% \text { Adición }\end{array}$ \\
\hline Portland con puzolana & II-Z & $\begin{array}{l}72-94 \% \text { Clínker } \\
6-28 \% \text { Z } \\
0-5 \% \text { Adición }\end{array}$ & $\begin{array}{l}\text { II/A-P } \\
\text { II/A-Q } \\
\text { II/B-P } \\
\text { II/B-Q }\end{array}$ & $\begin{array}{l}\text { 80-94 \% Clínker } \\
6-20 \% \text { P, Q } \\
0-5 \% \text { Adición } \\
\text { 65-79 \% Clinker } \\
21-35 \% \text { P, Q } \\
0-5 \% \text { Adición }\end{array}$ \\
\hline Portland con ceniza volante & II-C & $\begin{array}{l}72-94 \% \text { Clinker } \\
6-28 \% \text { C } \\
0-5 \% \text { Adición }\end{array}$ & $\begin{array}{l}\text { II/A-V } \\
\text { II/A-W } \\
\text { II/B-V } \\
\text { II/B-W }\end{array}$ & $\begin{array}{l}\text { 80-94 \% Clínker } \\
6-20 \% \text { V, W } \\
0-5 \% \text { Adición } \\
\text { 65-79 \% Clinker } \\
21-35 \% \text { V, W } \\
0-5 \% \text { Adición }\end{array}$ \\
\hline Portland con filler calizo & II-F & $\begin{array}{l}80-94 \% \text { Clínker } \\
6-15 \% \text { F } \\
0-5 \% \text { Adición }\end{array}$ & $\begin{array}{l}\text { II/A-L } \\
\text { II/B-L }\end{array}$ & $\begin{array}{l}\text { 80-94 \% Clínker } \\
6-20 \% \text { L } \\
\text { 0-5 \% Adición } \\
\text { 65-79 \% Clínker } \\
21-35 \% \text { L } \\
0-5 \% \text { Adición }\end{array}$ \\
\hline Portland con humo de sílice & & & II/A-D & $\begin{array}{l}90-94 \% \text { Clínker } \\
6-10 \% \text { D } \\
0-5 \% \text { Adición }\end{array}$ \\
\hline Portland con esquisto calcinado & & & $\begin{array}{l}\text { II/A-T } \\
\text { II/B-T }\end{array}$ & $\begin{array}{l}\text { 80-94 \% Clínker } \\
6-20 \% \text { T } \\
0-5 \% \text { Adición } \\
65-79 \% \text { Clínker } \\
21-35 \% \text { T } \\
0-5 \% \text { Adición }\end{array}$ \\
\hline Cemento de horno alto & $\begin{array}{l}\text { III-1 } \\
\text { III-2 }\end{array}$ & $\begin{array}{l}\text { 40-64 \% Clinker } \\
36-60 \% \text { S } \\
\text { 0-5 \% Adición } \\
\\
20-39 \% \text { Clínker } \\
61-80 \% \text { S } \\
0-5 \% \text { Adición }\end{array}$ & $\begin{array}{l}\text { III/A } \\
\text { III/B } \\
\text { III/C }\end{array}$ & $\begin{array}{l}\text { 35-64 \% Clínker } \\
36-65 \% \text { S } \\
\text { 0-5 \% Adición } \\
\text { 20-34 \% Clínker } \\
66-80 \% \text { S } \\
\text { 0-5 \% Adición } \\
\text { 5-19\% Clínker } \\
\text { 81-95\% S } \\
\text { 0-5 \% Adición }\end{array}$ \\
\hline
\end{tabular}


TABLA IV (Continuación)

Diferencias y semejanzas normas UNE 8030188 y ENV 197-1

\begin{tabular}{|c|c|c|c|c|}
\hline \multirow{2}{*}{ DESIGNACIÓN } & \multicolumn{2}{|r|}{ UNE 8030188} & \multicolumn{2}{|r|}{ ENV 197-1 } \\
\hline & Tipo & Composición & Tipo & Composición \\
\hline Cemento puzolánico & IV & $\begin{array}{l}\geq 60 \% \text { Clínker } \\
\leq 40 \% \text { z, C } \\
0-5 \% \text { Adición }\end{array}$ & $\begin{array}{l}\mathrm{IV} / \mathrm{A} \\
\mathrm{IV} / \mathrm{B}\end{array}$ & $\begin{array}{l}\text { 65-90 \% Clínker } \\
10-35 \% \text { D, P, Q, V } \\
\text { 0-5\% Adición } \\
\text { 45-64 \% Clínker } \\
36-55 \% \text { D, P, Q, V } \\
0-5 \% \text { Adición }\end{array}$ \\
\hline Cemento mixto & v & $\begin{array}{l}20-64 \% \text { Clinker } \\
36-80 \% \text { S, Z, C } \\
\text { 0-5\% Adición }\end{array}$ & & \\
\hline Cemento compuesto & & & $\begin{array}{l}\text { V/A } \\
\text { V/B }\end{array}$ & $\begin{array}{l}40-64 \% \text { Clínker } \\
18-30 \% \text { S } \\
\text { 18-30\% P, Q, V } \\
\text { 0-5 \% Adición } \\
\\
20-39 \% \text { Clínker } \\
30-50 \% \text { S } \\
30-50 \% \text { P, Q, V } \\
\text { 0-5 \% Adición }\end{array}$ \\
\hline Cemento aluminoso & $\mathrm{VI}$ & $100 \%$ Clínker A. & & \\
\hline
\end{tabular}

(*) El contenido de filler calizo se limita al $5 \%$.

(+) $6 \%-27 \%$ de escoria

$6 \%-23 \%$ de puzolana natural, ceniza volante.

$0 \%-5 \%$ de filler calizo.

Los cemento tipo II deben responder a la fómula: $1,0 \mathrm{~S}+1,25 \mathrm{Z}+1,25 \mathrm{C}+1,75 \mathrm{~F} \leq 35 \%$.

* De este modo, en la ENV no existen los cementos de "muy alta" resistencia, ni los de "baja" resistencia.

* En la ENV se distingue entre la resistencia normal (resistencia mecánica a la compresión de acuerdo con la EN 196-1, a los 28 días) y la resistencia a temprana edad, a 2 ó 7 dias, igual que ocurre en la norma UNE.

Para cada clase de resistencia normal, se definen dos clases de resistencia a edad temprana: una clase con resistencia temprana ordinaria, y una elevada indicada por $\mathrm{R}$ en la ENV o por $\mathrm{A}$ en la UNE.

En general, los valores de las especificaciones a corta edad en la ENV son inferiores a los de la UNE; la 35 A establece unas resistencia a 2 dias de $13,5 \mathrm{~N} / \mathrm{mm}^{2}$ y la equivalente en la ENV, la 32,5 $\mathrm{R}$ tan sólo $10 \mathrm{~N} / \mathrm{mm}^{2}$. Aunque las categorías 42,5 R ( $\geq 20 \mathrm{~N} / \mathrm{mm}^{2}$ a 2 dias) y $52,5 \mathrm{R}\left(\geq 30 \mathrm{~N} / \mathrm{mm}^{2}\right.$ a 2 dias) equivalen a la $45 \mathrm{~A}$ y a la $55 \mathrm{~A}$ y presentan las mismas especificaciones a 2 dias.

* En relación a las resistencias mínimas y máximas a 28 días, tanto en la norma UNE como en la ENV, el intervalo en el que se pueden mover los cementos es igual en las dos normas $\left(20 \mathrm{~N} / \mathrm{mm}^{2}\right)$, con ello se quiere establecer una uniformidad en los mismos.

La norma ENV, al igual que la norma española, no establece límite máximo para la categoría resistente superior (55, según la norma UNE o 52,5 en la ENV).

\section{Exigencias físicas y químicas}

En las exigencias físicas existen pocas diferencias. La norma UNE exige un tiempo de final de fraguado, lo que no hace la norma europea. El valor de estabilidad de volumen es igual en ambas normas.

En cuanto a las exigencias químicas, la ENV establece para los cementos CEM I y CEM III un valor de pérdida por calcinación ( $\leq 5 \%$ ) y no establece especificaciones para los demás, mientras que la Norma UNE limita la PPC para cada uno de los cementos considerados, oscilando desde $3,5 \%$ para los cementos Tipo I-O y $12 \%$ para los cementos Tipo V. 
* Los valores del residuo insoluble son iguales en ambas normas, aunque la ENV limita el valor para los cementos Tipos I y III y la Norma UNE limita también el RI para los cementos II-S y II-F.

* En cuanto el contenido de trióxido de azufre, en la ENV se limita éste entre 3,5\% y $4,0 \%$, según la clase del cemento, y la Norma UNE entre $4 \%$ y $4,5 \%$. Pero en la ENV este valor está especificado según las categorías resistentes, hecho que tan sólo se hace en la norma UNE en los cementos Tipo I-O y I y, por supuesto, por el tipo de adición.

* Las exigencias en el contenido de cloruros y la puzolanicidad son iguales en ambas normas, aunque en el caso de los cementos Tipo III, la ENV establece que el contenido en cloruros puede ser superior a $0,10 \%$, pero en tal caso se debe declarar el contenido real de cloruros.

\section{CALIDAD DE LOS CEMENTOS}

En relación a establecer vías para comprobar la calidad de los cementos, en los últimos años se han producido, tanto en España como en otros países europeos, cambios importantes.

En nuestro país, en la actualidad, existen dos caminos para legalizar la comercialización del cemento, que son la homologación y la certificación.

La homologación está a cargo del Ministerio de Industria, Comercio y Turismo, y la certificación se lleva a cabo a través de AENOR.

Con el Real Decreto 1313/1988 se declara obligatoria la homologación de los cementos para todo tipo de obras y productos prefabricados. En 1989, por Orden Ministerial, se establece que la certificación voluntaria AENOR de cementos es una alternativa a la homologación. Esto se debe a que los controles realizados para la certificación son más exigentes que los recogidos en la homologación.

Así, cualquier cemento que esté certificado por AENOR está directamente homologado por el Ministerio de Industria, Comercio y Turismo (MICY$\mathrm{T})$, aunque este hecho no se da en sentido contrario, y un cemento homologado no está directamente certificado.

La certificación es básica para mantener la calidad de los productos en el mercado, y contribuye a fomentar la competitividad, imprescindible cara a un Mercado Único Europeo, estableciendo limites a la competencia desleal.

Como se ha indicado anteriormente, en AENOR se establecen Comités de Certificación, cuyo objeto es verificar que los productos son conformes con las normas que les son aplicables, sirviendo al mismo tiempo para implantar en las empresas sistemas de asegurar la calidad a través de la concesión de marcas.

Con la entrada en vigor de la Directiva sobre Productos de Construcción (1 de diciembre de 1988), todos los países comunitarios deben implantar un sistema de Certificación de Cementos, que está siendo objeto de estudio por el CEN/TC51/WG13. De esta forma, los cementos que tengan la marca CE podrán circular libremente por toda la Comunidad Económica Europea.

Para poder implantar una Certificación Europea, antes hace falta una normativa adecuada. Así, la ENV 197-1 recoge no solamente lo expuesto hasta ahora - relativo a clasificación, composición de los cementos-, sino que también en ella se encuentran recogidos los criterios de conformidad con los mismos.

Todos los países tendrán que ir modificando sus esquemas para adaptarse a los criterios mencionados.

En la Norma UNE 8040388 , al igual que en la ENV 197-1, se establece que la conformidad de los cementos a las exigencias especificadas en las normas anteriores debe ser evaluada de forma continua y de acuerdo con los criterios que ella señala. Así, se especifica que los cementos serán verificados mediante un plan de control estadístico de calidad basado en una inspección continua del cemento producido; la inspección es llevada a cabo por el fabricante (autocontrol).

Sin embargo, mientras que en la norma UNE se hace constar que el control será supervisado por un organismo o laboratorio oficialmente reconocido, en la ENV este factor solamente se recoge como NOTA ADICIONAL, de forma que se indica: "Las regulaciones nacionales o internacionales pueden exigir que el autocontrol de los cementos CEM sea supervisado por un laboratorio de ensayo oficialmente reconocido".

En relación a los procedimientos generales para la verificación de la conformidad con los valores característicos especificados, la norma UNE establece que la verificación se basa en una inspección continua por muestreo, utilizando muestras puntuales de cemento tomadas de acuerdo con los Procedimientos indicados en la norma UNE 80 401, y la ENV indica exactamente lo mismo pero haciendo mención a la EN 196-7.

También en ambas normas se hace mención a que, para verificar la conformidad, las series de muestras 
deberán ser tomadas durante un período no menor de seis meses ni mayor de doce.

La frecuencia mínima de ensayos será:

Frecuencia mínima de ensayo UNE 80403

\begin{tabular}{|l|l|}
\hline \multicolumn{1}{|c|}{ Características } & N. ${ }^{\circ}$ de muestras \\
\hline $\begin{array}{l}\text { Resistencias } \\
\text { Sulfatos } \\
\text { Tiempo de fraguado } \\
\text { Estabilidad }\end{array}$ & 2 por semana \\
\hline Residuo insoluble & \\
Pérdida por calcinación & \\
Cloruros & \\
Puzolanicidad & \\
Propiedades especiales & \\
Componentes & \\
\hline
\end{tabular}

En la ENV 197-1 se recogen, en la tabla de frecuencias mínimas de ensayo, las mismas determinaciones y número de muestras, a excepción de las correspondientes a propiedades especiales, lógicamente por no tratarse en dicha norma este tipo de cementos. Tampoco en ella se establece el ensayo de determinación de los componentes.

En ambas normas, UNE 80403 y ENV 197-1, son idénticos los Criterios y Procedimientos de conformidad para las propiedades mencionadas.

Sin embargo, en la ENV 197-1, se señala que un ensayo que no cumpla con los requisitos establecidos en las tablas de exigencias mecánicas, físicas y químicas será clasificado como DEFECTO, haciendo además la distinción entre DEFECTOS MENORES Y DEFECTOS MAYORES:
Defecto: Cualquier no conformidad de un individuo con las prescripciones mecánicas, físicas y químicas.

Defecto Menor: Defecto que realmente no reduce mucho la posibilidad de empleo del cemento para el fin que se le ha dado.

Defecto Mayor: Defecto que corre el riesgo de provocar un fallo o reducir de forma importante la posibilidad de empleo del cemento para el fin al que ha sido destinado.

Defectuoso: Individuo que presenta uno o varios defectos.

Una cantidad de cemento en la que aparezca una o más muestras con defectos mayores no estará conforme con los requisitos de esta norma ENV.

Un defecto mayor se define como una desviación de las exigencias mecánicas, físicas o químicas tan notable que la aptitud del cemento, para su aplicación pretendida, probablemente se verá reducida y, en casos extremos, puede incluso originar fallos.

Si un resultado de un ensayo se desvía en cuantía mayor de la especificada en la tabla V, se calificará como DEFECTO MAYOR.

Para el resto de características, la norma no establece ninguna limitación que pudiera dar lugar a defectos mayores, quedando sólo calificados, independientemente de la cuantía de la desviación, como defectos menores o simplemente defectos.

\section{Agradecimientos}

A los Profesores Francisco Soria y José Calleja todo nuestro agradecimiento y cariño.

TABLA V

Defectos mayores

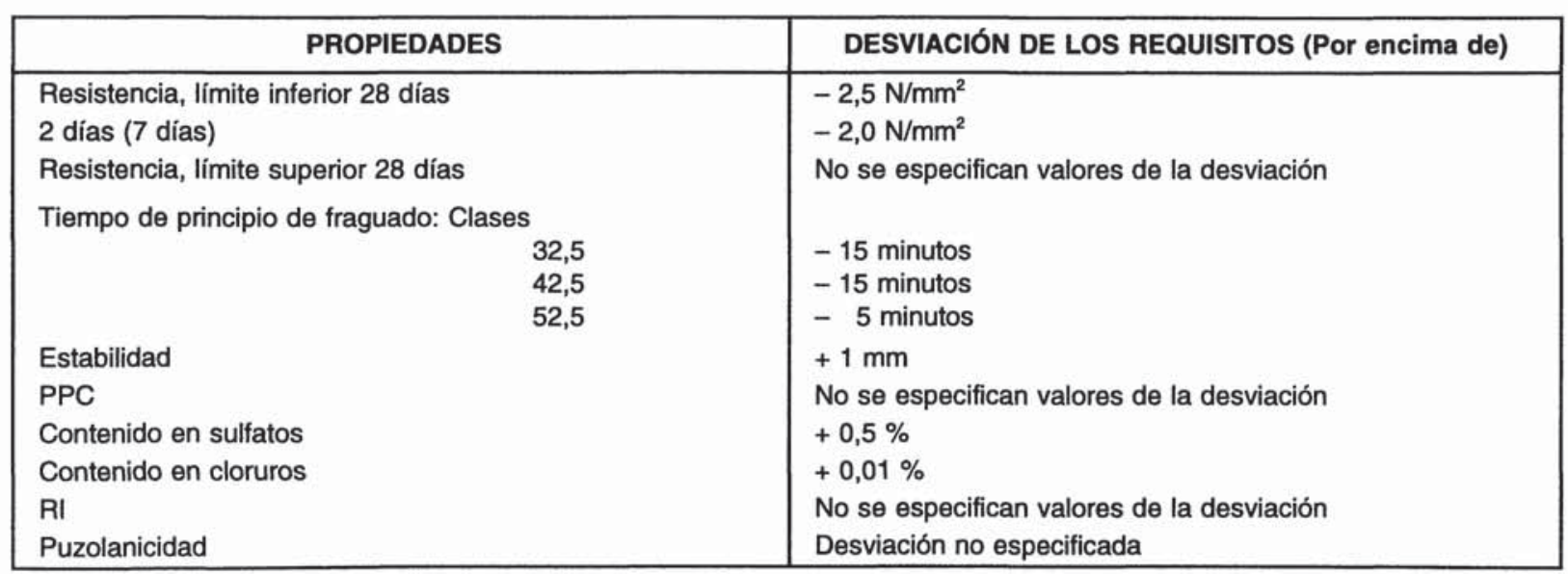




\section{BIBLIOGRAFÍA}

- F. SORIA (1990). Jornadas Técnicas de Certificación y Control de Calidad. Madrid.

- J. CALLEJA (1992). Cemento y Hormigón, N.․ 709, 1157-1182.

- Norma 80 301: "Cementos: Definiciones, clasificación y especificaciones".

- Norma 80 302: "Cementos: Especificaciones quimicas para sus componentes".

- Norma UNE 80 303: "Cementos: Cementos con características especiales"

- Norma UNE 80 305: "Cementos portland blancos".

- Norma UNE 80 401: "Cementos: Toma de muestras".

- Norma UNE 80 403: "Cementos. Control de la producción. Criterios de conformidad".

- ENV 197-1: "Cement: Composition, specifications and Conformity criteria. Part 1: Common Cements".

\section{publicaciones del ICCET/CSIC}

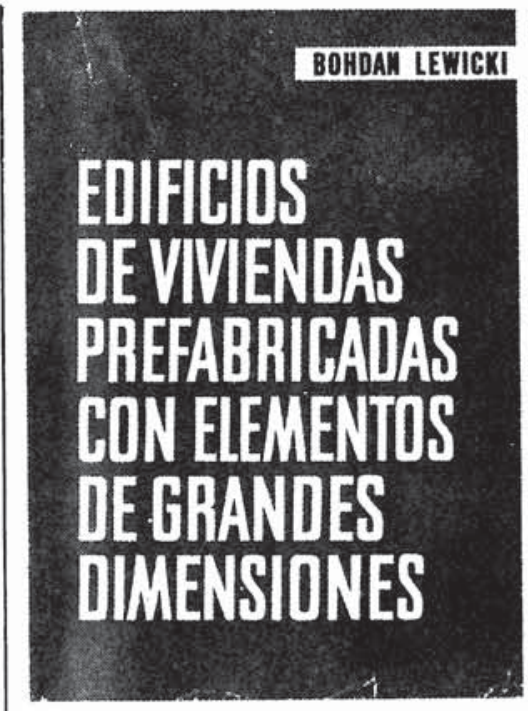

\section{Bohdan Lewicki}

Este libro trata de los problemas relativos a la construcción de los edificios de viviendas o públicos realizados con elementos prefa bricados de grandes dimensiones. Se han es. tudiado los problemas de arriostramiento asi como los que plantea la resistencia de los elementos y de la estructura; se han examinado las cuestiones de orden higrotérmico, acústico y de resistencia al fuego: también se ha profundizado en el estudio de la estanquidad de los muros exteriores y de las juntas.

La obra incluye numerosas ilustraciones que dan detalles de diversas soluciones, as como ejemplos de cálculo, tablas de valores numéricos, dlagramas y ábacos.

Un volumen encuadernado en tela, de $24 \times 17 \mathrm{~cm}$, compuesto de 616 págs.

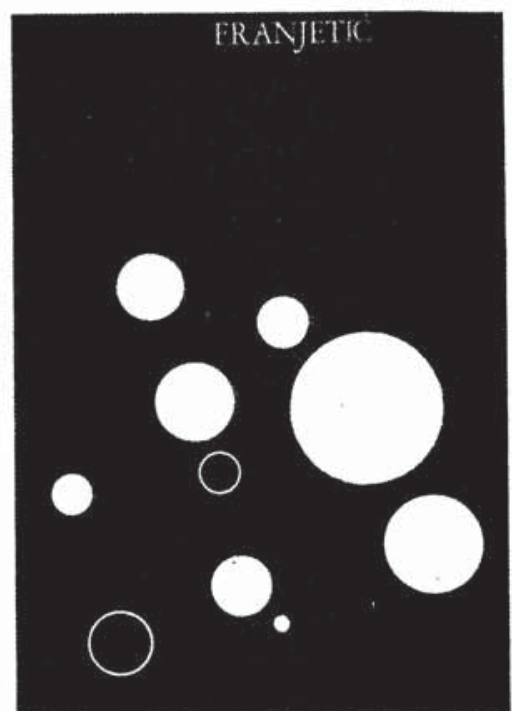

Zorislav Franjetić

En la obra de Franjetić se expone de una forma minuciosa, ordenada y sistemática, todo un cuerpo de doctrina que reúne el conocimiento actual sobre el endurecimiento rápido del hormigón. Parte el autor de los principios básicos y llega a las últimas con(t)cnicas $y$ consecuencias y realidades técnicas y económicas.

Es una obra de consulta, tanto para el investigador sobre la materia, como para el proyectista y el realizador y montador de plantas e instalaciones y equipos de curado y endurecimiento rápido.

Un volumen encuadernado en cartóné, de $17 \times 24,5 \mathrm{~cm}$, compuesto de 385 págs. 110 figuras y 10 tablas.

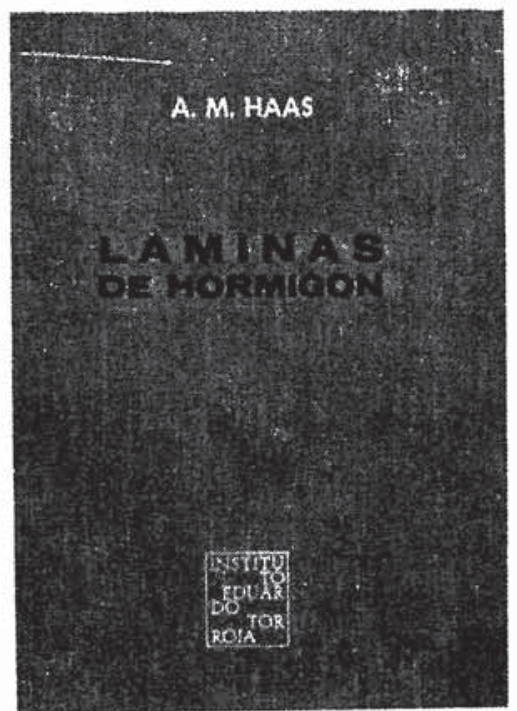

\section{A. M. Haas}

Al escribir este libro el autor intentó poner a disposición de los estudiantes y de los ingenieros unos conocimientos prácticos adecuados para servir de guia en el diseño y construcción de láminas delgadas de hormigón.

El autor está convencido de que el éxito en el diseño de una lámina exige, por parte del proyectista, un examen de las tres fases por las que pasa la materialización de la lámina: el diseño, el análisis estructural y la cons. trucción de la estructura.

Un volumen encuadernado en tela, de $17 \times 24,5 \mathrm{~cm}$, compuesto de 420 págs., 141 figuras, 22 fotograflas y 6 tablas. 